\title{
Electrical treeing in insulating resins with silica nanofillers
}

\author{
Josef Niedernhuber, Josef Kindersberger \\ Lehrstuhl für Hochspannungs- und Anlagentechnik \\ Technische Universität München \\ Munich, 80333 Germany \\ josef.niedernhuber@tum.de
}

\begin{abstract}
The study addresses the treeing-performance of unsaturated polyester resins with and without silica nanofillers and epoxy resin. Specimens with embedded needles mounted on a grounded plate are used. Time to electrical tree initiation, time to breakdown and growth behavior are determined. The influence of filler loading on the treeing performance as well as the effect of voltage amplitude are investigated. The results show that the resistance to treeing strongly depends on the type of matrix material used. While 1 wt. $\%$ nanofiller leads to improved resistance to electrical treeing, $5 \mathrm{wt}$. \% worsens the treeing performance.
\end{abstract}

Keywords—treeing; nano filler

\section{INTRODUCTION}

Electrical treeing is an important degradation mechanism in polymeric electrical insulation systems. In particular, the lifetime of electrical machines, switchgears and bushings may be affected by treeing $[1,2]$. To extend the durability of the equipment, tree inception has to be delayed and propagation of treeing should be slowed down [3]. It is known that the properties of insulating materials can be changed by adding just a few percent of nano filler. For the treeing resistance, researchers found out that the addition of nano filling material results in an increase of time to breakdown and a prolongation of the incubation period [4].

\section{EXPERIMENTAL}

\section{A. Materials}

Two unsaturated polyester resins (UP-resin A and B) and one epoxy-resin were examined as to their resistance to electrical treeing. The epoxy-resin is a bisphenol-F type singlecomponent impregnating resin. UP-resin A and resin B are two different kinds of single-component resins free of monomers. UP-resin A was filled with different loadings of a hydrophilic nano-silica ( $1 \mathrm{wt} . \%, 5 \mathrm{wt} . \%)$ with a primary particle size of $12 \mathrm{~nm}$. Mixing was realized mechanically by means of a disperser. Due to hydrogen bonding between filler and the base-polymer, viscosity of the uncured resin raises with the filler loading. After curing the dispersion of filler was checked using a FIB (focused ion beam) [5]. Nanoparticles are evenly distributed within the insulation material and no agglomerates are visible for both filling degrees, i.e. 1 wt. $\%$ and 5 wt. $\%$.

\section{B. Specimens}

To characterize the investigated materials a tip-plane arrangement was used. This configuration is a common way to determine the resistance to electrical treeing [6]. The length, width and height of the sample were $15 \mathrm{~mm}, 6 \mathrm{~mm}$ and $10 \mathrm{~mm}$, respectively. Needles with a tip-radius $r=5 \mu \mathrm{m}$ were placed in the casting mold before curing. The distance $d$ between the tip of the needle and the bottom of casting mold and ground electrode respectively was set to $3,5 \mathrm{~mm}$ (Fig. 1).

The curing was carried out at $120^{\circ} \mathrm{C}$ (UP-resin A and B) and $150^{\circ} \mathrm{C}$ (epoxy-resin), respectively. Low curing temperatures were used to reduce mechanical stress that can cause cracks or gaps especially around the tip of the needle. To achieve completely hardened specimens, time for curing had to be extended (Arrhenius equation). To avoid any influence of humidity on the results, specimens were stored at defined ambient conditions (50\% $\mathrm{RH}$, room temperature).

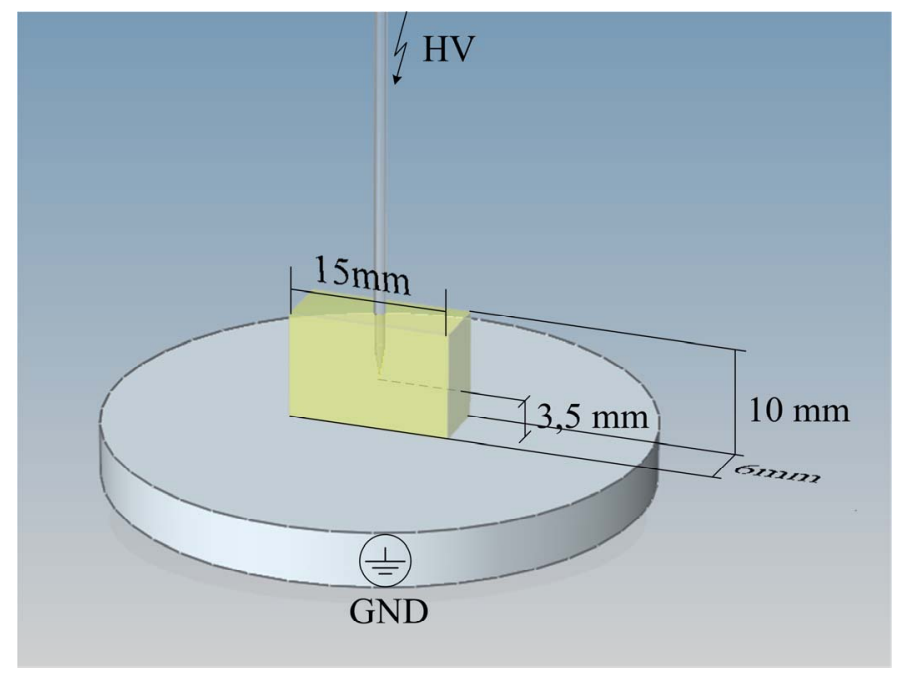

Fig. 1. Electrode arrangement and specimen dimensions for the electrical treeing test.

\section{Test-conditions}

The experiments were carried out at power-frequency $(f=50 \mathrm{~Hz})$. Applied voltage $U$ was varied in the range between $7 \mathrm{kV}$ and $25 \mathrm{kV}$ rms. The test cell was immersed in insulating ester to avoid flashover. The bottom side of the sample is 
coated with conductive varnish to establish good electrical contact between the specimen and the ground-electrode. Tree inception is detected visually by means of a camera focusing the tip of the needle whereby the detectable minimum tree length is approximately $15 \mu \mathrm{m}$. The shortest trees detected right after inception were $40 \mu \mathrm{m}$ in length.

\section{RESULTS AND DISCUSSION}

\section{A. Tree inception}

Voltages from $7 \mathrm{kV}$ to $25 \mathrm{kV}$ rms were applied for specimens of neat UP-resin A with a sample size of $n=3$ (for $7 \mathrm{kV}: n=1)$. The results show that the tree initiation time $t_{\mathrm{i}}$ decreases with increasing applied voltage $U$ (see Fig. 2).

The tree initiation process is associated with charge injection from the needle electrode - in real insulations from metallic inclusions $[7,8]$. One possible route to the formation of trees is that injected charge leads to impact excitation of molecular species and thus chemical degradation [7]. Another possible theory proposes a breaking of bonds by radiation emitted during charge recombination [7]. The typical correlation of time to inception $t_{\mathrm{i}}$ and voltage $U$ is $t_{\mathrm{i}} \propto U^{-\mathrm{n}}$ [8-9]. These findings are confirmed in our study. The correlation between inception time $t_{\mathrm{i}}$ and the voltage $U$ follows $t_{\mathrm{i}} \propto U^{-\mathrm{n}}$ with $t_{\mathrm{i}}=35 \cdot 10^{6} U^{-5}$ (see Fig. 2, dashed line).

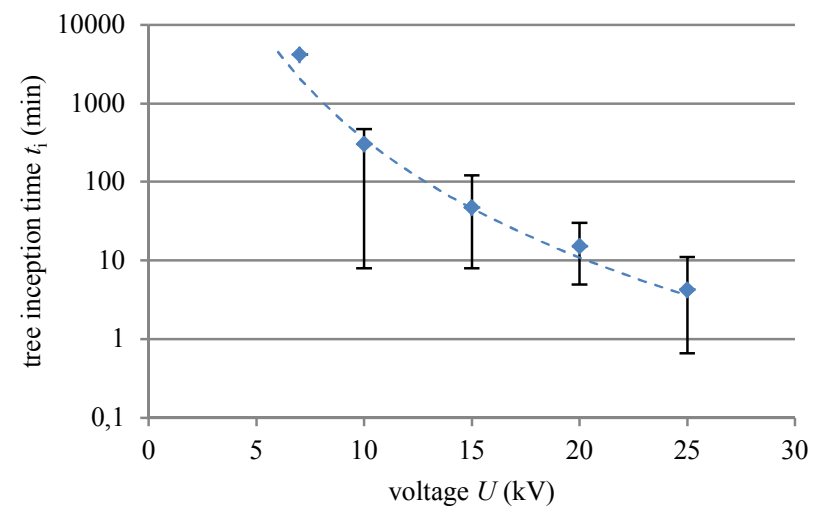

Fig. 2. Median value of tree inception times depending on test voltage for unfilled UP-resin $(n=3$, for $7 \mathrm{kV}: n=1)$. Bars represent maximum and minimum value. Dashed line: $t_{\mathrm{i}}=35 \cdot 10^{6} \cdot U^{-5}$.

Different materials are investigated with respect to their tree-inception times at $20 \mathrm{kV}$ (Fig. 3). For the unfilled resins, UP-resin A shows the highest median of the inception time $t_{\mathrm{i}}=10 \mathrm{~min}$, while the values for the epoxy-resin $\left(t_{\mathrm{i}}=1 \mathrm{~min}\right)$ and UP-resin B $\left(t_{\mathrm{i}}=0,5 \mathrm{~min}\right)$ are significantly lower. In particular for UP-resin A, adding 1 wt. $\%$ nano-silica $\left(t_{\mathrm{i}}=60 \mathrm{~min}\right)$ increases the inception-time, whereas $5 \mathrm{wt} . \%$ $\left(t_{\mathrm{i}}=2 \mathrm{~min}\right)$ filler leads to lower values of $t_{\mathrm{i}}$ compared to neat UP-resin A.

Assuming that differences between the neat polymers are material-dependent, variation of $t_{\mathrm{i}}$ for filled and unfilled UPresin A needs further explanation. It is confirmed that tree inception is caused by transfer of energy from the electrode to the material [7]. This energy causes a breaking of bonds in the polymer and thus degradation. Longer times to tree inception might be an indication of higher bonding forces in the polymer - which can be attributed to adding 1 wt. \% nanofillers. Hints for higher bonding strengths in nanocomposites are a phenomenon which is often reported $[10,11]$.

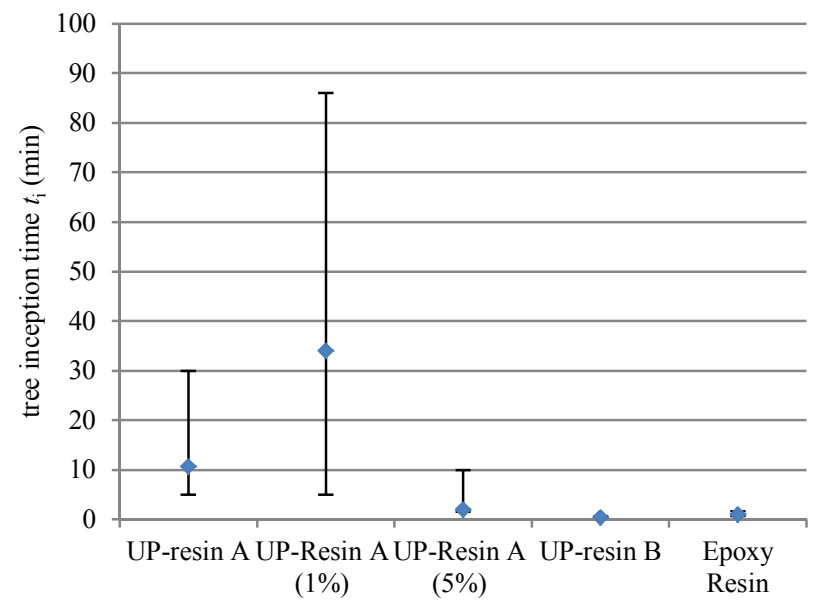

Fig. 3. Median of tree inception times $t_{\mathrm{i}}$ for different materials. Bars represent maximum and minimum value of $t_{\mathrm{i}}(V=20 \mathrm{kV}, f=50 \mathrm{~Hz})$.

The findings of a maximum value of enhanced properties at a certain filling degree can be explained by the interphasevolume-model that assumes a layer of interface surrounding the filler particles [12]. In this case, the performance for $5 \mathrm{wt}$. \% filled nanocomposites is even worse than for neat UP-resin A. This finding cannot be explained by the model and needs further investigation.

\section{B. Tree propagation}

Subsequently, the propagation properties of filled and unfilled UP-resin A as well as neat epoxy-resin were investigated. Fig. 4 shows the median of the extension of the trees of unfilled UP-resin A towards the ground electrode at different levels of voltage within the first $100 \mathrm{~h}$ of tree growth, i.e. the origin of the x-axis equals $t_{\mathrm{i}}$. The evaluation is based on pictures taken by the camera-system. Sample size is $n=3$ for each level of voltage.

At all voltages a rapid growth of the trees right after inception was detected, whereon for most specimens the tree growth decelerates until it stops eventually. There are two basic shapes of treeing-structures. Depending on the polymer, the radius and material of the needle electrode and the test voltage, branch-like or bush-like shapes of the trees are reported [13]. Combinations of the basic shapes to form a bush-branch structure are possible, in addition. All specimens in this study that show a deceleration to no further growth of the trees have a bush-like shape (see Fig. 5-1). The expansion of the trees shows a minimum at $U=15 \mathrm{kV}$. 


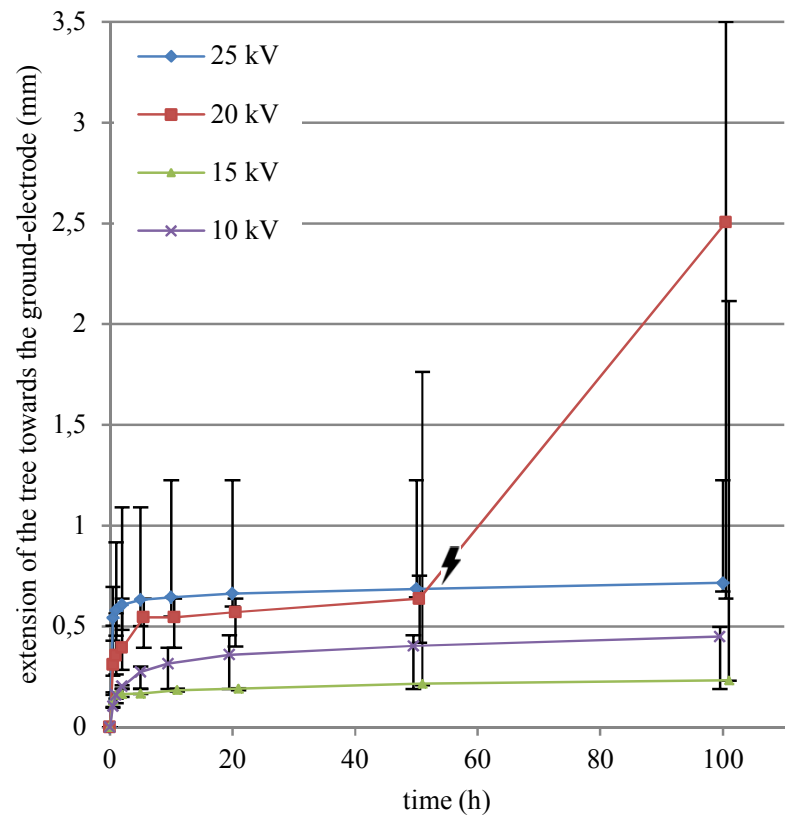

Fig. 4. Expansion of the longest tree channel directed towards the ground electrode depending on time. $0 \mathrm{~h}$ equals the inception time. The lightning mark indicates the time of breakdown of one specimen. Experiments are carried out at different voltage levels with unfilled UP-resin A $(f=50 \mathrm{~Hz}$, $r=5 \mu \mathrm{m}, d=3,5 \mathrm{~mm}$ ).

Two specimens stressed with $U=20 \mathrm{kV}$ showed a different behavior: For specimen 2 (see Fig. 5-2), a branch-like structure developed from the bush-like structure after $70 \mathrm{~h}$ of testing. This bush-like tree grew to an extent of $2,5 \mathrm{~mm}$ within another $30 \mathrm{~h}$. After that, no further growth can be observed for $100 \mathrm{~h}$ of voltage stress. Specimen 3 (see Fig. 5-3) showed a stable bushlike tree from hour 5 of testing onwards. After $50 \mathrm{~h}$ of stress, a fast growing branch developed reaching the ground electrode within another $5 \mathrm{~h}$ of testing.
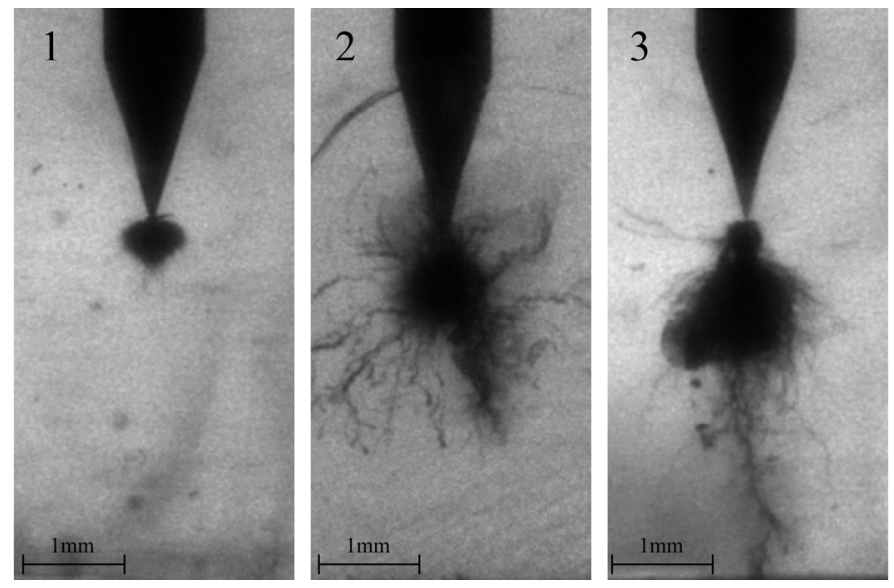

Fig. 5. UP-resin A treeing-needles $(r=5 \mu \mathrm{m})$ stressed with $20 \mathrm{kV}, 50 \mathrm{~Hz}$. 1: After $100 \mathrm{~h}$, bush-like. 2: After $100 \mathrm{~h}$, bush-branch structure. 3: After $60 \mathrm{~h}$, bush-branch with spike, breakdown.

High testing voltages abet the occurrence of bush-like tree structures, whereas lower voltages yield to branched trees [6].
The bush-branch-transition for UP-resin A at low testing voltages was not observed in this investigation.

The occurrence of different shapes of trees using identical test conditions and materials needs further investigation. Variations of internal mechanical stress due to dissimilar shrinking in the casting molds could be a possible reason for the big scatter and changes of the tree shape. Internal mechanical stress is supposed to be a factor which influences the treeing properties [14].

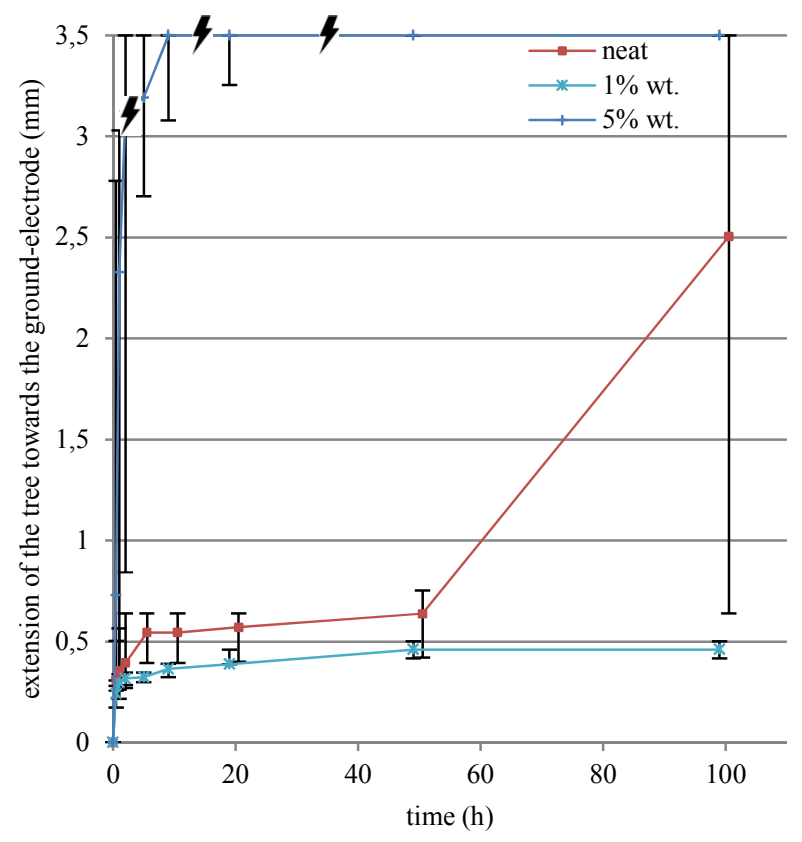

Fig. 6. Median of the expansion of the longest tree channel directed towards the ground electrode depending on time $(n=3)$. $0 \mathrm{~h}$ equals the inception time. The lightning mark indicates the time of breakdown of one specimen. Experiments are carried out at $20 \mathrm{kV}$ with unfilled and filled UP-resin A $(f=50 \mathrm{~Hz}, r=5 \mu \mathrm{m}, d=3,5 \mathrm{~mm})$.

Fig. 6 shows the median of tree expansion of UP-resin A with different loadings of silica-nano-filler tested at $20 \mathrm{kV}$ $(n=3)$. Specimens filled with $1 \mathrm{wt}$. \% show bush-like tree structures with slightly smaller extent than for the neat material (see Fig. 7-1, 7-2). Branch-like tree structures leading to breakdown are observed using $5 \mathrm{wt}$ \% silica filler (see Fig.7-3). The median of the time to breakdown for UP-resin A with 5 wt. $\%$ is $t_{\mathrm{b}}=14,5$ hours.

For the tree propagation of UP-resin A, the tendency of an improvement of treeing performance for $1 \mathrm{wt} . \%$ filler content as well as a worsening of the resistance to tree propagation for 5 wt. \% filler-content compared to neat resin is observed.

Epoxy-resin shows bush-like trees with continuous growth. Experiments were carried out with $U=20 \mathrm{kV}$. The time to breakdown $t_{\mathrm{b}}$ is in the range between $t_{\mathrm{b}}=0,75 \mathrm{~h}$ and $3,32 \mathrm{~h}$ with a median of $t_{\mathrm{b}}=1,1 \mathrm{~h}$. 

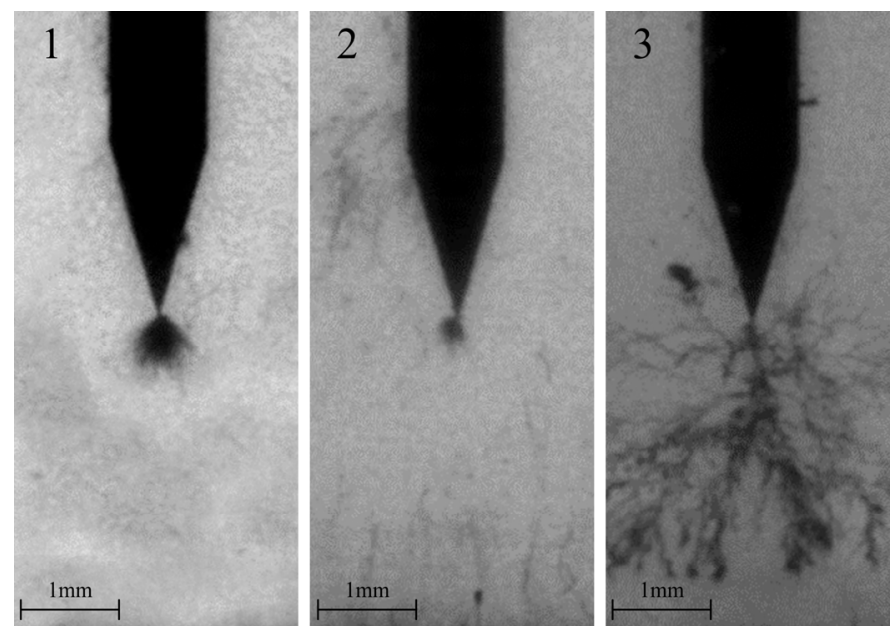

Fig. 7. Different forms of treeing for UP-resin A. The photos show the needle tips for different filler contents after $5 \mathrm{~h}$ of testing at $20 \mathrm{kV}$.

1: neat UP-resin A，2: 1 wt. \% filler content, 3: 5 wt. \% filler content.

This behavior is unexpected since silica nano fillers are supposed to improve the resistance to electrical treeing significantly $[15,16]$. For the time being no explanation can be found for the significant worsening of the treeing resistance at 5 wt. \% filler content. This subject will be studied further on.

\section{CONCLUSION}

Results for the electrical treeing properties of UP-resins, UP-resin nanocomposites and epoxy-resin containing tree initiation characteristics as well as tree propagation properties are presented. The following can be concluded:

- Tree inception time $t_{\mathrm{i}}$ and the shape of the trees depend on the kind of matrix material used. Neat UP-resin A shows higher values of $t_{\mathrm{i}}$ than UP-resin B and epoxyresin.

- Tree inception time $t_{\mathrm{i}}$ in UP-resin A is dependent of the applied voltage $U$ and follows $t_{\mathrm{i}}=35 \cdot 10^{6} \cdot U^{-5}$.

- The use of 1 wt. \% silica nano filler prolongs the incubation period and reduces the speed of tree propagation. 5 wt. $\%$ silica nano filler content has the opposite effect.

- Neat UP-resin A as well as 1 wt. \% nanocomposite show slowly growing bush-like tree structures. 5 wt. $\%$ nanocomposite results in fast-growing branch-like shapes of the tree.

- At the same experimental conditions, different shapes of trees for neat UP-resin A may occur.

\section{ACKNOWLEDGMENT}

The authors want to thank ELANTAS Beck, especially Dr. Klaus-W. Lienert and Gunther Baumgarten for their support producing specimen and supplying materials.

\section{REFERENCES}

[1] Dissado, L.A. and Fothergill, G.C., "Electrical degradation and breakdown in polymers", Peter Peregrinus Ltd., London, UK, 1992

[2] Vogelsang, R.; Weiers, T.; Fröhlich, K. and Brütsh, R., "Electrical breakdown in high-voltage winding insulations of different manufacturing qualities," Electrical Insulation Magazine, IEEE , vol.22, no.3, pp.5,12, May-June 2006

[3] Vogelsang, R.; Farr, T. and Fröhlich, K., "The effect of barriers on electrical tree propagation in composite insulation materials," Dielectrics and Electrical Insulation, IEEE Transactions on , vol.13, no.2, pp.373,382, April 2006

[4] Danikas, M.G. and Tanaka, T., "Nanocomposites-a review of electrical treeing and breakdown," Electrical Insulation Magazine, IEEE , vol.25, no.4, pp.19,25, July-Aug. 2009

[5] Anglhuber, M. and Kindersberger, J., "Quantification of surface erosion and microscopic analysis of particle distribution in polymer nanocomposites," Dielectrics and Electrical Insulation, IEEE Transactions on , vol.19, no.2, pp.408,413, April 2012

[6] Dissado, L.A.; Dodd, S.J.; Champion, J. V.; Williams, P. I. and Alison, J.M., "Propagation of electrical tree structures in solid polymeric insulation," Dielectrics and Electrical Insulation, IEEE Transactions on , vol.4, no.3, pp.259,279, Jun 1997

[7] Dissado, L.A., "Understanding electrical trees in solids: from experiment to theory," Solid Dielectrics, 2001. ICSD '01. Proceedings of the 2001 IEEE 7th International Conference on, vol., no., pp.15,26, 2001

[8] Raetzke, S.; Ohki, Y.; Imai, T.; Tanaka, T. and Kindersberger, J., "Tree initiation characteristics of epoxy resin and epoxy/clay nanocomoposite," Dielectrics and Electrical Insulation, IEEE Transactions on, vol.16, no.5, pp.1473,1480, October 2009

[9] Tanaka, T. "Comprehensive understanding of treeing V-t characteristics of epoxy nanocomposites", 17th International Symposium on High Voltage Engineering (ISH), Proceedings of the, paper No. E-008, Hannover, Germany, 2011

[10] Roy, M.; Nelson, J.K.; MacCrone, R.K.; Schadler, L.S.; Reed, C.W. and Keefe, R., "Polymer nanocomposite dielectrics-the role of the interface," Dielectrics and Electrical Insulation, IEEE Transactions on , vol.12, no.4, pp.629,643, Aug. 2005

[11] El-Hag, A.H.; Simon, L.C.; Jayaram, S. H. and Cherney, E. A., "Physicochemical properties of silica filled silicone rubber nanocomposites [electrical insulation applications]," Electrical Insulation and Dielectric Phenomena, 2004. CEIDP '04. 2004 Annual Report Conference on, vol., no., pp.688,691, 17-20 Oct. 2004

[12] Raetzke, S. and Kindersberger, J., "Role of interphase on the resistance to high-voltage arcing, on tracking and erosion of silicone $/ \mathrm{SiO}_{2}$ nanocomposites," Dielectrics and Electrical Insulation, IEEE Transactions on , vol.17, no.2, pp.607,614, April 2010

[13] Auckland, D. W.; Cooper, J. M. and Varlow, B.R., "Factors affecting electrical tree testing," Science, Measurement and Technology, IEE Proceedings A, vol.139, no.1, pp.9,13, Jan 1992

[14] David, E.; Parpal, J. -L and Crine, J. -P, "Influence of internal mechanical stress and strain on electrical performance of polyethylene electrical treeing resistance," Dielectrics and Electrical Insulation, IEEE Transactions on , vol.3, no.2, pp.248,257, Apr 1996

[15] Iizuka, T. and Tanaka, T., "Effects of nano silica filler size on treeing breakdown lifetime of epoxy nanocomposites," Properties and Applications of Dielectric Materials, 2009. ICPADM 2009. IEEE 9th International Conference on the , vol., no., pp.733,736, 19-23 July 2009

[16] Iizuka, T.; Uchida, K. and Tanaka, T., "Different voltage endurance characteristics of epoxy/silica nanocomposites prepared by two kinds of dispersion methods," Electrical Insulation and Dielectric Phenomena, 2007. CEIDP 2007. Annual Report - Conference on ,pp.236,239, 14-17 Oct. 2007 